\title{
Dietary patterns and hearing loss in older men enrolled in the Caerphilly Study
}

\author{
Nicola E. Gallagher ${ }^{1 *}$, Chris C. Patterson ${ }^{1}$, Charlotte E. Neville ${ }^{1}$, John Yarnell ${ }^{1} \dagger$, Yoav Ben-Shlomo ${ }^{2}$, \\ Anne Fehily ${ }^{3}$, John E. Gallacher ${ }^{4}$, Natalie Lyner ${ }^{1}$ and Jayne V. Woodside ${ }^{1}$ \\ ${ }^{1}$ Centre for Public Health, Queen's University, Belfast BT12 6BJ, UK \\ ${ }^{2}$ School of Social and Community Medicine, University of Bristol, Canynge Hall, Bristol BS8 2PS, UK \\ ${ }^{3}$ MRC Epidemiology Unit, Llandough Hospital, Cardiff CF2 3AS, UK \\ ${ }^{4}$ Department of Psychiatry, University of Oxford, Oxford OX3 7JX, UK
}

(Submitted 23 January 2018 - Final revision received 5 November 2018 - Accepted 8 January 2019 - First published online 23 January 2019)

\section{Abstract}

The association between dietary patterns (DP) and prevalence of hearing loss in men enrolled in the Caerphilly Prospective Study was investigated. During 1979-1983, the study recruited 2512 men aged 45-59 years. At baseline, dietary data were collected using a semiquantitative FFQ, and a 7-d weighed food intake (WI) in a $30 \%$ subsample. Five years later, pure-tone unaided audiometric threshold was assessed at 0.5, 1, 2 and $4 \mathrm{kHz}$. Principal component analysis (PCA) identified three DP and multiple logistic and ordinal logistic regression models examined the association with hearing loss (defined as pure-tone average of frequencies $0.5,1,2$ and $4 \mathrm{kHz}>25 \mathrm{~dB}$ ). Traditional, healthy and high-sugar/low-alcohol DP were found with both FFQ and WI data. With the FFQ data, fully adjusted models demonstrated significant inverse association between the healthy DP and hearing loss both as a dichotomous variable $(\mathrm{OR}=0.83$; $95 \% \mathrm{CI} 0 \cdot 77,0.90$; $P<0.001)$ and as an ordinal variable (OR $=0.87 ; 95 \% \mathrm{CI} 0.81,0.94 ; P<0.001)$. With the WI data, fully adjusted models showed a significant and inverse association between the healthy DP and hearing loss (OR $=0.85 ; 95 \%$ CI $0.73,0.99 ; P<0.03)$, and a significant association between the traditional DP (per fifth increase) and hearing loss both as a dichotomous variable (OR $=1 \cdot 18 ; 95 \%$ CI $1 \cdot 02,1 \cdot 35 ; P=0 \cdot 02)$ and as an ordinal variable $(\mathrm{OR}=1 \cdot 17 ; 95 \% \mathrm{CI} 1.03,1.33 ; P=0.02)$. A healthy DP was significantly and inversely associated with hearing loss in older men. The role of diet in age-related hearing loss warrants further investigation.

\section{Key words: Hearing loss: Dietary patterns: Older men: Ageing}

Hearing loss is highly prevalent in older people and can reduce quality of life substantially ${ }^{(1,2)}$, with detrimental effects on emotional health ${ }^{(3-5)}$ and on cognitive function ${ }^{(6-8)}$. Hearing loss is often described as an inevitable decline that occurs during the ageing process ${ }^{(1,9)}$, however, emerging research suggests that potentially modifiable risk factors, including risk factors previously related to CVD risk ${ }^{(10,11)}$, may be associated with a decreased or increased risk of hearing loss. This has prompted investigation into the possibility that certain nutrients and foods may also be associated with the incidence of hearing loss. Higher intake of $n-3$ fatty acids ${ }^{(10,12)}$, oily fish ${ }^{(10,12,13)}$, $\mathrm{Mg}^{(14)}$, vitamin intake, including vitamins $\mathrm{A}^{(15)}, \mathrm{B}_{12}{ }^{(16-18)} \mathrm{C}^{(14)}$ and $\mathrm{E}^{(15)}$, antioxidant intake, including $\beta$-carotene ${ }^{(14)}$, and moderate alcohol consumption ${ }^{(19)}$ have been associated with a lower incidence of hearing loss. Conversely, Shargorodsky et $a{ }^{(20)}$ found that the overall intake of vitamins $\mathrm{C}, \mathrm{E}$ and $\beta$-carotene was not associated with the incidence of hearing loss in men. Additionally, a high cholesterol intake ${ }^{(21)}$, a high consumption of food with a high glycaemic load ${ }^{(22)}$ and excessive alcohol consumption ${ }^{(23)}$ have been associated with an increased incidence of hearing loss. However, some of these studies have used only self-reported measures of hearing loss rather than objective measures which are preferable in this context ${ }^{(20,24,25)}$. Since associations have been reported between the above dietary factors and hearing loss, it seems plausible that certain dietary patterns (DP) may also be associated with hearing loss.

In recent years, DP analysis has become a widely used method of investigating the relationship between diet and disease $^{(26)}$. This technique adopts a holistic approach of examining diet and can be a useful complementary approach when examining specific individual nutrients, to more effectively capture the interaction between various nutrients ${ }^{(26,27)}$. Two main types of DP analysis can be carried out: a priori and

Abbreviations: CaPS, Caerphilly Prospective Study; dBA, unaided pure-tone binaural threshold; DP, dietary pattern; PAL, physical activity level; PCA, principal component analysis; PTA, pure-tone average; WI, weighed food intake.

* Corresponding author: N. E. Gallagher, email ngallagher17@qub.ac.uk

$\dagger$ Statement of author death: John Yarnell has died since the writing of this manuscript. 
a posteriori methods. A priori methods include dietary indices, such as the Mediterranean diet score, which are based on nutritional recommendations and guidelines ${ }^{(28)}$, whilst a posteriori methods use multivariate statistical techniques such as factor analysis, principal component analysis (PCA) and cluster analysis $^{(26)}$ to derive the patterns within the dietary data ${ }^{(28)}$. For this analysis, PCA was performed to derive a posteriori DP.

To the best of our knowledge, there have been no previous studies that examined a posteriori DP in relation to hearing loss. Spankovich et al. ${ }^{(29)}$ carried out a priori analysis and examined the Healthy Eating Index in relation to audiological thresholds, demonstrating an association between a healthy eating pattern and lower high-frequency thresholds in adults aged 20-69 years. However, a posteriori analysis may hold some advantages over a priori analysis, in that this approach is data driven and does not rely on scientific guidelines or nutritional recommendations ${ }^{(30)}$. The a posteriori approach gives a true representation of what the DP of a given population actually are, however, the DP only represents the cohort they were derived from and may not be generalisable to other populations. In this study, we investigated the association between a posteriori DP and hearing loss in men aged 45-59 years enrolled in the Caerphilly Prospective Study (CaPS) ${ }^{(31)}$. Prevalence of hearing loss was carried out 5 years after dietary assessment. We hypothesised that a healthier DP would be associated with a reduced prevalence of hearing loss.

\section{Methods}

\section{Study population}

CaPS began recruitment between 1979 and 1983 (baseline). The original cohort consisted of 2512 men who were aged between 45 and 59 years and lived in Caerphilly or the surrounding villages in Wales, UK. No exclusion criteria were applied. Subsequent examinations took place at 5-year intervals ${ }^{(32)}$. At phase 2, 561 men were lost to follow-up, therefore, an additional 447 men were included in the study, giving a new total of 2398 men $^{(33)}$. The initial aims of the study were to investigate ischaemic heart disease and the associations with various factors including cholesterol, fibrinogen, plasma viscosity, testosterone and insulin ${ }^{(34)}$. The baseline sample of 2512 men were the focus of this study.

\section{Ethics}

All CaPS participants gave written informed consent and the study had the approval of the local research ethics committee and adhered to the guidelines contained within the Declaration of Helsinki of 1975 as revised in 1983.

\section{Dietary data}

A self-administered, semi-quantitative fifty-six-item FFQ was completed during baseline examination ${ }^{(35)}$. The FFQ measured usual consumption of a range of foods. Frequency and quantity of intake of breads, fats, dairy products, sugar, alcohol, coffee and tea were asked for. For some of these foods, such as fats, dairy products and sugar, average intake per week for the family was requested. For such items, in order to estimate the individual intake, the family intake stated for the FFQ was divided by a 'total family score'. To obtain this score, an adult or toddler aged 5 years or older was assigned a value of 1 , a child aged between 1 and 4 years was given a value of $0 \cdot 5$, and an infant under the age of 1 year was assigned a value of 0 as their contribution to the family intake was assumed to be negligible $^{(35)}$. Frequency alone was measured for cereals, fruits, vegetables, eggs, meat, fish, confectionery and drinks. A 30\% subsample of the men also completed a 7-d weighed food intake (WI) to validate the FFQ as a more robust measure of dietary intake ${ }^{(35)}$. Pearson correlation coefficients were 0.3-0.4 across food items (alcohol 0.75), representing weak but statistically significant correlations ${ }^{(35)}$. Of the 764 men who completed the WI, only 665 men (87\%) had maintained a satisfactory record and were included in this analysis ${ }^{(36)}$. FFQ data were available for the full cohort (2512 men) and WI data were available for 665 men.

\section{Auditory assessment}

Pure-tone unaided binaural threshold $\left(\mathrm{dB}_{\mathrm{A}}\right)$ was assessed at four different frequencies $(0 \cdot 5,1,2$ and $4 \mathrm{kHz})$ with a Bosch audiometer and sound-reducing cups during the second phase, 5 years after the baseline examination. Audiometric assessment was performed in a community clinic environment where background ambient noise was approximately $50 \mathrm{~dB}_{\mathrm{A}}{ }^{(37)}$. Assessment began at $0.5 \mathrm{kHz}$ and $50 \mathrm{~dB}_{\mathrm{A}}$. The sound level was decreased by $10 \mathrm{~dB}_{\mathrm{A}}$ until the sound could no longer be detected, and the sound was then increased and decreased by $5 \mathrm{~dB}_{\mathrm{A}}$ until a threshold level was found. This technique was repeated for other frequencies ${ }^{(37)}$. The pure-tone average (PTA) threshold was calculated as the average of the four frequencies $(0.5,1,2$ and $4 \mathrm{kHz})$ and both ears. Hearing loss was defined as $\mathrm{PTA}_{0.5-4 \mathrm{kHz}}>25 \mathrm{~dB}^{(37)}$. Audiometric data were available for 1886 men.

\section{Assessment of covariates}

Anthropometry parameters, including height and weight, were measured using a Holtain stadiometer and a beam balance, respectively. Blood pressure was recorded by one observer using a Hawksley random zero mercury sphygmomanometer and a full twelve-lead electrocardiogram was performed and Minnesota coded by two experienced readers. The men were invited to attend a clinic the following morning, after fasting overnight, to obtain a venous blood sample from which blood cholesterol was assessed ${ }^{(38)}$. Physical activity at work was estimated using the Health Insurance Plan questionnaire, and leisure time activity was assessed using the Minnesota Leisure Time Activity questionnaire. For the current analysis, a physical activity level (PAL) score was calculated by summing the activity levels at work, activity levels to and from work and leisure time physical activity. Two points were awarded if very active at work, one point was given if occasionally active at work, one point was given if one or more miles were travelled to work through cycling or walking and one point was scored if 
consistent leisure activity was completed ${ }^{(39)}$. Participants were classified as non-smokers, ex-smokers or current smoking, which included pipe or cigar smokers, light cigarette smokers $(<15 /$ d), moderate cigarette smokers $(15-24 /$ d) or heavy cigarette smokers $(\geq 25 / d)$. Social class was determined according to occupation; manual or non-manual, according to the classification of occupations and coding index $(1980)^{(40,41)}$.

\section{Statistical analysis}

SPSS Statistics for Windows version 20 (IBM Corp.) was used for all statistical analyses, including $t$ tests, $\chi^{2}$ tests, logistic and ordinal logistic regression models and PCA. All variables were normally distributed. To carry out PCA, all food and drink items in the FFQ and WI separately were condensed into thirty-two groups (online Supplementary Table S1). In the initial stages of data analysis, to decide which method would give more accurate results, the WI food items were condensed into the same thirty-two food groups as the FFQ food items but also into fortythree food groups, as the WI comprised a larger number of food items. However, it was decided to condense the WI food items into the same thirty-two food groups as the FFQ items for ease of comparison of DP and as a validation of the FFQ.

The process of PCA aggregates food items/groups according to how well they correlate with one another. The decision of how many factors to retain in the analysis was made by examining the break in the scree plot, along with eigenvalues $>1$ and the interpretability of the factors obtained. Orthogonal varimax rotation was then used to create a simpler structure with greater interpretability ${ }^{(42)}$. The DP generated were then named according to the positive and negative factor loadings of food and drink items. Factor loadings $<-0 \cdot 2$ in magnitude were considered low and factor loadings $>0.2$ in magnitude were considered high, which aided naming of the patterns.

Multiple logistic and ordinal logistic regression models were used to examine the association between the DP with hearing loss. DP were divided into fifths and each participant received a quintile ranking for each of the three DP. Hearing loss was first assessed as a dichotomous variable with a cut point of $>25 \mathrm{~dB}$ PTA threshold to compare hearing loss with no hearing loss ( $\leq 25 \mathrm{~dB}$ PTA threshold) and examined using logistic regression. Hearing loss was also assessed as an ordinal variable according to the categories: no hearing loss $\leq 25 \mathrm{~dB}$, mild $>25-40 \mathrm{~dB}$, moderate $>40-60 \mathrm{~dB}$ and severe hearing loss $>60 \mathrm{~dB}$ and examined using ordinal logistic regression.

The models were adjusted for potential confounding factors. These included factors associated with both hearing loss and DP in the current data set. This was assessed by linear regression analysis. Other possible confounders from the current literature were also considered. The models were first adjusted for age (model 1), then again adjusted for occupation (model 2) (in the form of social class; manual or non-manual ${ }^{(37)}$ ) and then further adjusted for the continuous variables: BMI, systolic blood pressure (SBP), PAL score, total cholesterol and the categorical variable; smoking (non-smokers, ex-smokers, pipe or cigar smokers, light cigarette smokers, moderate cigarette smokers or heavy cigarette smokers) (model 3). Other models were investigated, including adjustment for age, occupation, smoking and PAL score, as it is possible the other variables may be intermediate markers rather than confounders; however, the effect sizes were similar, therefore, the model proposed above (model 3) was maintained. Height was also explored as a possible confounder but did not significantly influence the models and therefore was not considered for further analysis. For the WI data, further adjustment for energy intake was explored but did not significantly affect the models, therefore data are not presented. Statistical significance was defined as $P<0 \cdot 05$.

\section{Results}

Baseline characteristics of all 2512 men recruited for CaPS are shown in Table 1 . The men were also grouped into two categories: those with hearing loss (PTA $>25 \mathrm{~dB}$ ) and those with no hearing loss ( $\leq 25 \mathrm{~dB}$ PTA) (Table 1$)$. Compared with men without hearing loss, men with hearing loss were significantly older, shorter and lighter and were more likely to be current smokers and manual workers. Those with hearing loss and those with no hearing loss had similar BMI, PAL score and total cholesterol levels.

Three DP were determined by PCA using the FFQ data traditional, healthy, high sugar/low alcohol. Together, these three DP explained $23.4 \%$ of the total variance. The traditional pattern had high factor loading scores for the following foods: red meat, vegetables, processed meat, whitefish/shellfish, eggs, organ meat, poultry, lard, butter, potato, cheese, milk, oily fish, grains, fried potato, beer, sugar, tap water, soft drinks, tea and confectionery. The healthy pattern was characterised by high positive loadings for cereals, fruit, high-fibre bread, confectionery, vegetables, natural juices, margarine, milk and cream and negative loadings for beer, lard and butter. The high-sugar/lowalcohol pattern had high factor loading scores for tea, sugar, milk, white bread, confectionery, fried potato and negative loadings for wine, other alcoholic drinks, coffee, natural juices, high-fibre bread and beer (online Supplementary Table S2).

Logistic regression analysis of the FFQ data, using a cut point of $25 \mathrm{~dB}$ for hearing loss, showed a protective effect for the healthy DP after adjustment for age (OR per fifth $=0.78,95 \% \mathrm{CI}$ $0.73,0.83 ; P<0.001)$ and a detrimental effect for the high-sugar/ low-alcohol pattern model (OR per fifth $=1 \cdot 12$, 95\% CI $1 \cdot 05$, $1.20 ; P=0.001)$. The former association was hardly altered after adjustment for potential confounding factors (OR per fifth $=0.83 ; 95 \%$ CI $0.77,0.90 ; P<0.001$ ) but was consistent with chance variability for the high-sugar/low-alcohol pattern as this association became insignificant $(P=0 \cdot 16)$ (Table 2$)$. Similarly, only the healthy DP remained significantly inversely associated with hearing loss after adjustment for potential confounding factors in the ordinal logistic regression analysis of the FFQ data (OR per fifth $=0.87,95 \%$ CI 0.81, 0.94; $P<0.001$ ) (Table 3).

For the ordinal logistic regression, the categories of hearing loss were no hearing loss $\leq 25 \mathrm{~dB}$, mild $>25-40 \mathrm{~dB}$, moderate $>40-60 \mathrm{~dB}$ and severe $>60 \mathrm{~dB}$. Data are presented with OR of having greater hearing loss (reference; severe hearing loss) for those in each quintile of DP (reference; Q1). The OR as a trend are also presented which represents a one-unit increase in hearing loss category for each higher quintile of DP. 
Table 1. Baseline characteristics of all men aged 45-59 years in the Caerphilly Prospective Study grouped according to having hearing loss (pure-tone average $($ PTA $)>25 \mathrm{~dB}$ ) or no hearing loss $(\text { PTA } \leq 25 \mathrm{~dB})^{*} \dagger$

(Numbers and percentages; mean values and standard deviations)

\begin{tabular}{|c|c|c|c|c|c|c|c|}
\hline \multirow[b]{3}{*}{ Characteristics } & \multicolumn{7}{|c|}{ Baseline Caerphilly participants } \\
\hline & \multicolumn{2}{|c|}{$\begin{array}{l}\text { All participants } \\
\quad(n \text { 2512) }\end{array}$} & \multicolumn{2}{|c|}{$\begin{array}{c}\text { No hearing loss } \\
\text { (PTA } \leq 25 \mathrm{~dB})(n 890)\end{array}$} & \multicolumn{2}{|c|}{$\begin{array}{c}\text { Hearing loss } \\
(\mathrm{PTA}>25 \mathrm{~dB})(n \text { 996) }\end{array}$} & \multirow[b]{2}{*}{$P$} \\
\hline & $n$ & $\%$ & $n$ & $\%$ & $n$ & $\%$ & \\
\hline Age (years) & & & & & & & $<0.001$ \\
\hline Mean & \multicolumn{2}{|c|}{$52 \cdot 1$} & \multicolumn{2}{|c|}{$50 \cdot 8$} & \multicolumn{2}{|c|}{$53 \cdot 0$} & \\
\hline SD & \multicolumn{2}{|c|}{4.5} & \multicolumn{2}{|c|}{$4 \cdot 2$} & \multicolumn{2}{|c|}{4.4} & \\
\hline Height (m) & & & & & & & $<0.001$ \\
\hline Mean & \multicolumn{2}{|c|}{1.71} & \multicolumn{2}{|c|}{1.72} & \multicolumn{2}{|c|}{1.70} & \\
\hline SD & \multicolumn{2}{|c|}{0.06} & \multicolumn{2}{|c|}{0.06} & \multicolumn{2}{|c|}{0.06} & \\
\hline Weight (kg) & \multirow{2}{*}{\multicolumn{2}{|c|}{$76 \cdot 6$}} & & & & & 0.003 \\
\hline Mean & & & \multicolumn{2}{|c|}{$77 \cdot 6$} & \multicolumn{2}{|c|}{$76 \cdot 0$} & \\
\hline SD & \multicolumn{2}{|c|}{$12 \cdot 1$} & \multicolumn{2}{|c|}{11.4} & \multicolumn{2}{|c|}{11.7} & \\
\hline $\mathrm{BMI}\left(\mathrm{kg} / \mathrm{m}^{2}\right)$ & & & & & & & 0.49 \\
\hline Mean & \multicolumn{2}{|c|}{$26 \cdot 2$} & \multicolumn{2}{|c|}{$26 \cdot 2$} & \multicolumn{2}{|c|}{$26 \cdot 1$} & \\
\hline SD & \multicolumn{2}{|c|}{3.6} & \multicolumn{2}{|c|}{3.3} & \multicolumn{2}{|c|}{3.6} & \\
\hline Systolic blood pressure & & & & & & & 0.04 \\
\hline Mean & & & & & & & \\
\hline SD & & & & & & & \\
\hline Total cholesterol & & & & & & & 0.57 \\
\hline Mean & & & & & & & \\
\hline SD & & & & & & & \\
\hline Physical activity level (with no physical activity) & 501 & 19.9 & 152 & $17 \cdot 1$ & 160 & $16 \cdot 1$ & 0.15 \\
\hline Current smoker & 1387 & 56 & 426 & 48 & 555 & 56 & $<0.001$ \\
\hline Manual worker & 1668 & 68 & 488 & 56 & 728 & 74 & $<0.001$ \\
\hline Dietary pattern factor loading scores & & & & & & & \\
\hline Traditional FFQ & 0 & 1 & -0.009 & 0.83 & 0.036 & 0.97 & 0.28 \\
\hline Healthy FFQ & 0 & 1 & 0.256 & 0.99 & -0.095 & 0.97 & $<0.001$ \\
\hline High-sugar/low-alcohol FFQ & 0 & 1 & -0.104 & 1.04 & 0.034 & 0.97 & 0.003 \\
\hline Traditional WI & 0 & 1 & $-0 \cdot 101$ & 1.07 & 0.107 & 0.95 & 0.02 \\
\hline Healthy WI & 0 & 1 & $0 \cdot 182$ & 1.06 & -0.132 & 0.90 & $<0.001$ \\
\hline High-sugar/low-alcohol WI & 0 & 1 & -0.022 & 0.90 & 0.014 & 1.01 & 0.67 \\
\hline
\end{tabular}

WI, weighed food intake.

* Independent samples $t$ tests were used for continuous variables and $x^{2}$ tests for categorical variables.

$\dagger n$-value for WI data no hearing loss $n_{\max } 236$ and hearing loss $n_{\max } 279$.

Three similar DP were determined using factor analysis with the WI data - traditional, healthy, high sugar/low alcohol. Together, these three DP explained $20 \cdot 2 \%$ of the total variance. The traditional pattern was characterised by high loadings for butter, white bread, lard, sugar, tea, potatoes, red meat and eggs and negative loadings for cooking oil, high-fibre bread, cereals and fruit juices. The healthy pattern had high factor loadings for fruit, wine, confectionery, vegetables, other soft drinks, fruit juices, cheese, high-fibre bread, other alcoholic drinks, cream, coffee and red meat and negative loadings for white bread, tea, sugar and cooking oil. The high-sugar/low-alcohol pattern was characterised by high factor loadings for milk, cereals, tea, confectionery, cream and sugar and negative loadings for beer, organ meat, eggs, red meat, potatoes fried, coffee, oily fish and lard (online Supplementary Table S3).

After adjustment for potential confounding factors using the WI data, logistic regression analysis demonstrated a significant association between the traditional pattern and greater risk of hearing loss (OR per fifth $=1.18 ; 95 \%$ CI 1.02, 1.35; $P=0.02$ ) and between the healthy pattern and reduced risk of hearing loss (OR per fifth $=0.85 ; 95 \%$ CI $0.73,0.99 ; P=0.03$ ) (Table 4). Ordinal logistic regression analysis of the WI data showed that the traditional DP remained significantly associated with hearing loss after adjustment for potential confounding factors (OR per fifth $=1 \cdot 17,95 \%$ CI $1.03,1.33 ; P=0.02$ ). The healthy DP only lost statistical significance once the model was fully adjusted (OR per fifth $=0.87,95 \%$ CI $0.76,1 \cdot 00 ; P=0.06$ ) (Table 5).

Table 6 provides a summary of the results of the logistic and ordinal logistic regression analyses using both FFQ and WI data. This table shows that for the healthy DP, three out of four analyses showed a statistically significant inverse association with hearing loss, whereas the traditional DP demonstrated a significant positive association with hearing loss in two out of four analyses. The high-sugar/low-alcohol DP was not significantly associated with hearing loss in any analyses in the fully adjusted models.

\section{Discussion}

The main finding from this study was that a healthy DP was significantly inversely associated with prevalence of hearing loss. This was found using hearing loss as a dichotomous variable (cut point of $25 \mathrm{~dB}$ ) for both FFQ and WI data, and using hearing loss as an ordinal variable (no hearing loss 
Table 2. Logistic regression analysis of the association between hearing loss (pure-tone average $>25 \mathrm{~dB})$ and quintiles (Q) of dietary pattern factor score for FFQ data from the Caerphilly Prospective Study*

(Odds ratios and $95 \%$ confidence intervals)

\begin{tabular}{|c|c|c|c|c|c|c|}
\hline & \multicolumn{6}{|c|}{ Dietary pattern } \\
\hline & \multicolumn{2}{|c|}{ Traditional } & \multicolumn{2}{|c|}{ Healthy } & \multicolumn{2}{|c|}{ High sugar/low alcohol } \\
\hline & OR & $95 \% \mathrm{Cl} \dagger$ & OR & $95 \% \mathrm{Cl} \dagger$ & OR & $95 \% \mathrm{Cl} \dagger$ \\
\hline \multicolumn{7}{|l|}{ Model 1 - adjustment for age } \\
\hline Q1 (low pattern adherence; $n_{\max } 503$ ) & 1.00 & Ref. & 1.00 & Ref. & 1.00 & Ref. \\
\hline Q2 $\left(n_{\max } 503\right)$ & $1 \cdot 15$ & $0.86,1.53$ & 0.69 & $0.51,0.93$ & $1 \cdot 14$ & $0.86,1.53$ \\
\hline Q3 $\left(n_{\max } 503\right)$ & 1.01 & $0.75,1.35$ & 0.66 & $0.49,0.86$ & 1.52 & $1 \cdot 13,2.04$ \\
\hline Q4 ( $\left.n_{\max } 503\right)$ & 1.35 & $1.00,1.82$ & 0.43 & $0.32,0.58$ & $1 \cdot 26$ & $0.93,1.69$ \\
\hline Q5 (high pattern adherence; $n_{\max } 503$ ) & $1 \cdot 14$ & $0.84,1.53$ & $1 \cdot 21$ & $0.89,1.67$ & 0.89 & $0.66,1.19$ \\
\hline Per fifth $\ddagger$ & 1.04 & $0.97,1.11$ & 0.78 & $0.73,0.83$ & $1 \cdot 12$ & $1.05,1.20$ \\
\hline $\begin{array}{l}P_{\text {for trend }} \\
\text { Model } 2 \text { - adjustment for age and occupa }\end{array}$ & \multicolumn{2}{|c|}{0.31} & \multicolumn{2}{|c|}{$<0.001$} & \multicolumn{2}{|r|}{0.001} \\
\hline Q1 $\left(n_{\max } 503\right)$ & $1 \cdot 00$ & Ref. & $1 \cdot 00$ & Ref. & 1.00 & Ref. \\
\hline Q2 $\left(n_{\max } 503\right)$ & 0.90 & $0.66,1.22$ & 0.89 & $0.65,1.22$ & 1.03 & $0.76,1.39$ \\
\hline Q3 $\left(n_{\max } 503\right)$ & 1.01 & $0.75,1.36$ & 0.63 & $0.46,0.87$ & $1 \cdot 13$ & $0.84,1.53$ \\
\hline Q4 ( $\left.n_{\max } 503\right)$ & 0.90 & $0.67,1.23$ & 0.67 & $0.49,0.92$ & 1.43 & $1.05,1.95$ \\
\hline Q5 ( $\left.n_{\max } 503\right)$ & $1 \cdot 20$ & $0.88,1.64$ & 0.46 & $0.33,0.63$ & $1 \cdot 15$ & $0.84,1.58$ \\
\hline Per fifth $\ddagger$ & 1.04 & $0.97,1.1$ & 0.83 & $0.77,0.89$ & 1.06 & $0.99,1.14$ \\
\hline$P_{\text {for trend }}$ & \multicolumn{2}{|c|}{0.29} & \multicolumn{2}{|c|}{$<0.001$} & \multicolumn{2}{|r|}{0.08} \\
\hline \multicolumn{7}{|c|}{$\begin{array}{l}\text { Model } 3 \text { - adjustment for age, occupation, BMI, systolic } \\
\text { blood pressure, smoking, physical activity level and total cholesterol }\end{array}$} \\
\hline Q1 $\left(n_{\max } 503\right)$ & 1.00 & Ref. & 1.00 & Ref. & 1.00 & Ref. \\
\hline Q2 ( $\left.n_{\max } 503\right)$ & 0.90 & $0.65,1.23$ & 0.89 & $0.64,1.24$ & 1.05 & $0.77,1.44$ \\
\hline Q3 $\left(n_{\max } 503\right)$ & 0.99 & $0.72,1.35$ & 0.64 & $0.46,0.88$ & $1 \cdot 12$ & $0.82,1.52$ \\
\hline Q4 $\left(n_{\max } 503\right)$ & 0.89 & $0 \cdot 65,1.22$ & 0.70 & $0.50,0.97$ & 1.46 & $1.06,2.01$ \\
\hline Q5 ( $\left.n_{\max } 503\right)$ & $1 \cdot 16$ & $0.84,1.61$ & 0.45 & $0.32,0.64$ & $1 \cdot 10$ & $0.79,1.53$ \\
\hline Per fifth $\ddagger$ & 1.03 & $0.96,1.11$ & 0.83 & $0.77,0.90$ & 1.06 & $0.98,1.14$ \\
\hline$P_{\text {for trend }}$ & \multicolumn{2}{|c|}{0.44} & \multicolumn{2}{|c|}{$<0.001$} & \multicolumn{2}{|r|}{$0 \cdot 16$} \\
\hline
\end{tabular}

Ref., reference.

* Hearing loss defined as PTA $>25 \mathrm{~dB}$.

† OR for hearing loss in comparison to Q1 (reference).

$\ddagger$ OR for hearing loss per fifth of dietary pattern factor score.

$\leq 25 \mathrm{~dB}$, mild $>25-40 \mathrm{~dB}$, moderate $>40-60 \mathrm{~dB}$, severe $>60 \mathrm{~dB}$ ) for the FFQ data, with the WI healthy DP only losing statistical significance $(P=0 \cdot 06)$. Prevalence of hearing loss was assessed 5 years after dietary assessment; however, the findings presented are cross-sectional, therefore, the possibility of reverse causality cannot be discounted.

There was limited evidence showing that a traditional DP was associated with an increased prevalence of hearing loss using logistic and ordinal logistic regression analyses of the WI data but not with the FFQ data. The high-sugar/low-alcohol DP was significantly associated with hearing loss in age-adjusted models for both logistic and ordinal logistic regression analyses of the FFQ data; but after further adjustment, this statistical significance was lost.

Very few studies investigated DP and hearing loss previously. Spankovich et $a l .{ }^{(29)}$ investigated the Healthy Eating Index and hearing loss and found that a more healthy diet was associated with better hearing at high frequencies in adults aged 20-69 years. Diet quality has also been examined in relation to concurrent vision and hearing impairment. Individuals in the lowest quintile compared to the highest quintile of dietary score had double the risk of having concurrent vision and hearing impairment $^{(43)}$. To our knowledge, a posteriori DP have not previously been examined in relation to hearing loss.

A greater number of studies demonstrated significant associations between dietary factors and hearing loss. A diet high in oily fish ${ }^{(10,12,13)}, n-3$ fatty acids ${ }^{(10,12)}$, vitamins and antioxidants $^{(14,16-18,24)}$ and moderate alcohol consumption ${ }^{(19)}$ has been associated with a reduced risk of hearing loss, which supports our finding that a healthier diet is associated with reduced risk of hearing loss. Conversely, a high cholesterol intake $^{(21)}$ and a high intake of foods with a high glycaemic load $^{(22)}$ have been associated with an increased risk of hearing loss.

Our study has examined DP in relation to hearing loss and not only individual dietary factors. Examining individual nutrients or foods may not be optimal, due to the interaction between nutrients. DP analysis, on the other hand, investigates the synergistic effects of nutrients and foods, producing a more comprehensive approach of examining the overall diet ${ }^{(27)}$. DP may be more likely to produce a significant association with the risk of morbidity when compared with single nutrients ${ }^{(27)}$. Also, since fewer statistical tests are carried out in DP analysis, there is less likelihood of obtaining results due to chance (type I error) ${ }^{(27)}$.

There is the possibility that the associations found between dietary factors and hearing loss are due to the association between CVD risk factors and age-related hearing loss ${ }^{(11,45,46)}$. Elevated TAG levels, elevated resting heart rate, low level of HDL-cholesterol, high SBP, a history of smoking and increased BMI have been associated with an increased risk of hearing 
Table 3. Ordinal logistic regression analysis of the association between categories of hearing loss (no hearing loss $\leq 25 \mathrm{~dB}$, mild $>25-40 \mathrm{~dB}$, moderate $>40-60 \mathrm{~dB}$, severe $>60 \mathrm{~dB}$ ) and quintiles (Q) of dietary pattern factor score for FFQ data from the Caerphilly Prospective Study* (Odds ratios and $95 \%$ confidence intervals)

\begin{tabular}{|c|c|c|c|c|c|c|}
\hline & \multicolumn{6}{|c|}{ Dietary pattern } \\
\hline & \multicolumn{2}{|c|}{ Traditional } & \multicolumn{2}{|c|}{ Healthy } & \multicolumn{2}{|c|}{ High sugar/low alcohol } \\
\hline & OR & $95 \% \mathrm{Cl} \dagger$ & OR & $95 \% \mathrm{Cl} \dagger$ & OR & $95 \% \mathrm{Cl} \dagger$ \\
\hline \multicolumn{7}{|l|}{ Model 1 - adjustment for age } \\
\hline Q1 (low pattern adherence; $n_{\max } 503$ ) & 1.00 & Ref. & 1.00 & Ref. & 1.00 & Ref. \\
\hline Q2 $\left(n_{\max } 503\right)$ & 0.90 & $0 \cdot 68,1.19$ & 0.94 & $0.71,1.25$ & 1.08 & $0.81,1.43$ \\
\hline Q3 $\left(n_{\max } 503\right)$ & 1.04 & $0 \cdot 79,1.38$ & 0.66 & $0.50,0.88$ & $1 \cdot 28$ & $0.97,1.70$ \\
\hline Q4 $\left(n_{\max } 503\right)$ & 0.93 & $0.70,1.23$ & 0.60 & $0.45,0.79$ & 1.72 & $1 \cdot 30,2 \cdot 27$ \\
\hline Q5 (high pattern adherence; $n_{\max } 503$ ) & 1.24 & $0.94,1.65$ & 0.42 & $0.32,0.56$ & 1.38 & $1.04,1.83$ \\
\hline Per fifth $\ddagger$ & 1.05 & $0.98,1.12$ & 0.80 & $0.76,0.86$ & $1 \cdot 12$ & $1.05,1.19$ \\
\hline $\begin{array}{l}P_{\text {for trend }} \\
\text { Model } 2 \text { - adjustment for age and occupa }\end{array}$ & \multicolumn{2}{|r|}{0.14} & \multicolumn{2}{|c|}{$<0.001$} & \multicolumn{2}{|r|}{0.001} \\
\hline Q1 $\left(n_{\max } 503\right)$ & 1.00 & Ref. & 1.00 & Ref. & 1.00 & Ref. \\
\hline Q2 $\left(n_{\max } 503\right)$ & 0.92 & $0 \cdot 70,1 \cdot 23$ & 1.05 & $0.79,1.39$ & 0.97 & $0.73,1.29$ \\
\hline Q3 $\left(n_{\max } 503\right)$ & 1.05 & $0.80,1.39$ & 0.76 & $0.57,1.00$ & $1 \cdot 11$ & $0.84,1.48$ \\
\hline Q4 $\left(n_{\max } 503\right)$ & 0.95 & $0.72,1.27$ & 0.77 & $0.58,1.02$ & 1.40 & $1.05,1.87$ \\
\hline Q5 $\left(n_{\max } 503\right)$ & $1 \cdot 27$ & $0.96,1.69$ & 0.56 & $0.42,0.75$ & $1 \cdot 10$ & $0.82,1.48$ \\
\hline Per fifth $\ddagger$ & 1.05 & $0.99,1.12$ & 0.86 & $0.81,0.92$ & 1.06 & $0.99,1.13$ \\
\hline$P_{\text {for trend }}$ & \multicolumn{2}{|r|}{0.12} & \multicolumn{2}{|c|}{$<0.001$} & \multicolumn{2}{|r|}{0.08} \\
\hline \multicolumn{7}{|c|}{$\begin{array}{l}\text { Model } 3 \text { - adjustment for age, occupation, BMI, systolic } \\
\text { blood pressure, smoking, physical activity level and total cholesterol }\end{array}$} \\
\hline Q1 $\left(n_{\max } 503\right)$ & 1.00 & Ref. & 1.00 & Ref. & 1.00 & Ref. \\
\hline Q2 $\left(n_{\max } 503\right)$ & 0.92 & $0 \cdot 69,1 \cdot 23$ & 1.07 & $0.79,1.43$ & 0.99 & $0.74,1.33$ \\
\hline Q3 $\left(n_{\max } 503\right)$ & 1.03 & $0.77,1.37$ & 0.79 & $0.59,1.06$ & 1.09 & $0.81,1.46$ \\
\hline Q4 $\left(n_{\max } 503\right)$ & 0.95 & $0.71,1.27$ & 0.82 & $0.61,1.11$ & 1.45 & $1.08,1.95$ \\
\hline Q5 $\left(n_{\max } 503\right)$ & $1 \cdot 23$ & $0.91,1.65$ & 0.58 & $0.42,0.79$ & 1.06 & $0.78,1.44$ \\
\hline Per fifth $\ddagger$ & 1.04 & $0.98,1.12$ & 0.87 & $0.81,0.94$ & 1.05 & $0.98,1.13$ \\
\hline$P_{\text {for trend }}$ & \multicolumn{2}{|r|}{0.20} & \multicolumn{2}{|c|}{$<0.001$} & \multicolumn{2}{|r|}{0.14} \\
\hline
\end{tabular}

DP, dietary pattern; Ref., reference.

* Categories of hearing loss: no hearing loss $\leq 25 \mathrm{~dB}$, mild $>25-40 \mathrm{~dB}$, moderate $>40-60 \mathrm{~dB}$ and severe $>60 \mathrm{~dB}$.

† OR of having greater hearing loss (reference; severe hearing loss) for those in each quintile of DP (reference; Q1).

$\ddagger$ OR for a one-unit increase in hearing loss category for each higher quintile of DP.

loss ${ }^{(11,44-47)}$. It has been hypothesised that the link between CVD risk factors and hearing loss may be due to reduced blood flow to the cochlea of the inner ear, which will reduce the ability to hear optimally ${ }^{(11)}$. Since the above studies ${ }^{(11,44-47)}$ have shown that there could be a link between CVD risk factors and hearing loss, there is the possibility that certain dietary changes, which are likely to reduce CVD risk, may also have a beneficial influence on hearing loss.

Key strengths of our investigation include its large cohort size of 2512 men. Also, although an FFQ was used to obtain dietary data from the full cohort, a 7-d WI was also completed in a $30 \%$ subset. This robust dietary assessment method is unusual in epidemiological studies. In a previous validation study of the FFQ using the WI, Pearson correlation coefficients were $0 \cdot 3-0 \cdot 4$ across food items (alcohol $0 \cdot 75$ ), representing weak but statistically significant correlations ${ }^{(35)}$. Furthermore, hearing loss was measured using audiometry, in contrast to many other studies that have used only self-reported measures ${ }^{(20,24,25)}$.

Nevertheless, there are several limitations to consider. Only men were investigated in the study and these men were all living in the town of Caerphilly, or surrounding villages in Wales, therefore, the generalisability of the results of this study to the wider population may be limited. Further limitations were that men with conductive hearing loss, otosclerosis etc. were not excluded from the analysis, information on hearing aid use was not collected and information was not available on individuals who were lost to follow-up.

The FFQ was also limited for some food groups, particularly for fruits. This may have resulted in some measurement error in the DP found from the FFQ ${ }^{(48)}$. The weighed intake also has some negatives as people may change their dietary habits when they know they are weighing their food and assessing their dietary intake. Also, auditory assessment was not conducted in an optimal setting (i.e. in a soundproof booth), but the technique used was validated in seventy participants with full clinical assessment using a soundproof booth. Good correlations were found between procedures at each of the four frequencies $(r \text { 0.69-0.93 })^{(37)}$. The DP analysis was conducted in the full cohort of 2512 men, whilst audiometric assessment was only carried out in 1886 men. Ideally, the DP analysis would be carried out only in those with audiometric assessment.

Furthermore, although adjustment was made for numerous potential confounding factors, there is still the possibility of residual confounding. In particular, exposure to noise, socioeconomic status and CVD risk factors may not have been fully accounted for. Information on chronic conditions such as heart disease, stroke, diabetes and hypertension were collected, however, we did not have access to these data for the current analysis. Occupation (in the form of social class) was adjusted 
Table 4. Logistic regression analysis of the association between hearing loss (pure-tone average $>25 \mathrm{~dB}$ ) and quintiles $(\mathrm{Q})$ of dietary pattern factor score for weighed food intake data from the Caerphilly Prospective Study*

(Odds ratios and $95 \%$ confidence intervals)

\begin{tabular}{|c|c|c|c|c|c|c|}
\hline & \multicolumn{6}{|c|}{ Dietary pattern } \\
\hline & \multicolumn{2}{|c|}{ Traditional } & \multicolumn{2}{|c|}{ Healthy } & \multicolumn{2}{|c|}{ High sugar/low alcohol } \\
\hline & OR & $95 \% \mathrm{Cl} \dagger$ & OR & $95 \% \mathrm{Cl} \dagger$ & OR & $95 \% \mathrm{Cl} \dagger$ \\
\hline \multicolumn{7}{|l|}{ Model 1 - adjustment for age } \\
\hline Q1 (low pattern adherence; $n_{\max } 133$ ) & 1.00 & Ref. & 1.00 & Ref. & 1.00 & Ref. \\
\hline Q2 $\left(n_{\max } 133\right)$ & $1 \cdot 17$ & $0.67,2.03$ & 0.80 & $0.46,1.39$ & 0.79 & $0.45,1.39$ \\
\hline Q3 $\left(n_{\max } 133\right)$ & 0.76 & $0.43,1.35$ & 0.70 & $0.40,1.22$ & 1.20 & $0.68,2.12$ \\
\hline Q4 $\left(n_{\max } 133\right)$ & 1.60 & $0.92,2.77$ & 0.42 & $0.24,0.74$ & 0.90 & $0.51,1.60$ \\
\hline Q5 (high pattern adherence; $n_{\max } 133$ ) & 0.52 & $0.29,0.92$ & 0.97 & $0.55,1.72$ & 1.31 & $0.74,2 \cdot 32$ \\
\hline Per fifth $\ddagger$ & 1.22 & $1.07,1.38$ & 0.82 & $0.72,0.93$ & 0.94 & $0.83,1.07$ \\
\hline $\begin{array}{l}P_{\text {for trend }} \\
\text { Model } 2-\text { adjustment for age and occupa }\end{array}$ & \multicolumn{2}{|c|}{0.002} & \multicolumn{2}{|c|}{0.002} & \multicolumn{2}{|r|}{0.37} \\
\hline Q1 $\left(n_{\max } 133\right)$ & 1.00 & Ref. & 1.00 & Ref. & 1.00 & Ref. \\
\hline Q2 $\left(n_{\max } 133\right)$ & 1.93 & $1.07,3.48$ & $1 \cdot 16$ & $0.65,2.09$ & $0 \cdot 83$ & $0.46,1.49$ \\
\hline Q3 $\left(n_{\max } 133\right)$ & $2 \cdot 14$ & $1 \cdot 19,3.86$ & 0.97 & $0.54,1.74$ & 0.67 & $0.38,1.17$ \\
\hline Q4 $\left(n_{\max } 133\right)$ & 1.23 & $0.67,2 \cdot 27$ & 0.90 & $0.50,1.62$ & 1.05 & $0.59,1.87$ \\
\hline Q5 $\left(n_{\max } 133\right)$ & $2 \cdot 60$ & $1.43,4.70$ & 0.55 & $0.29,1.01$ & 0.77 & $0.43,1.37$ \\
\hline Per fifth $\ddagger$ & $1 \cdot 16$ & $1.02,1.32$ & 0.87 & $0.76,0.99$ & 0.97 & $0.85,1.11$ \\
\hline$P_{\text {for trend }}$ & \multirow{2}{*}{\multicolumn{2}{|c|}{0.03}} & \multirow{2}{*}{\multicolumn{2}{|c|}{0.04}} & & \multirow[t]{2}{*}{0.65} \\
\hline $\begin{array}{l}\text { Model } 3 \text { - adjustment for age, occupation, } \\
\text { blood pressure, smoking, physical activit }\end{array}$ & & & & & & \\
\hline Q1 $\left(n_{\max } 133\right)$ & 1.00 & Ref. & 1.00 & Ref. & 1.00 & Ref. \\
\hline Q2 $\left(n_{\max } 133\right)$ & 1.89 & $1.03,3.47$ & 1.08 & $0.58,1.99$ & 0.86 & $0.47,1.59$ \\
\hline Q3 $\left(n_{\max } 133\right)$ & $2 \cdot 17$ & $1 \cdot 18,4.01$ & 0.93 & $0.50,1.74$ & 0.71 & $0.39,1.28$ \\
\hline Q4 $\left(n_{\max } 133\right)$ & 1.30 & $0.69,2.46$ & 0.86 & $0.46,1.60$ & 0.92 & $0.50,1.68$ \\
\hline Q5 $\left(n_{\max } 133\right)$ & 2.67 & $1.43,5.01$ & 0.49 & $0.25,0.96$ & 0.85 & $0.46,1.56$ \\
\hline Per fifth $\ddagger$ & $1 \cdot 18$ & $1.02,1.35$ & 0.85 & $0.73,0.99$ & 0.97 & $0.85,1.12$ \\
\hline$P_{\text {for trend }}$ & \multicolumn{2}{|r|}{0.02} & \multicolumn{2}{|r|}{0.03} & \multicolumn{2}{|r|}{0.69} \\
\hline
\end{tabular}

Ref., reference.

* Hearing loss defined as PTA $>25 \mathrm{~dB}$.

† OR for hearing loss in comparison to Q1 (reference).

$\ddagger$ OR for hearing loss per fifth of dietary pattern factor score.

for, which would have accounted for some workplace noise exposure as well as socio-economic status. There is, however, a possibility of residual confounding by exposure to noise as part of employment not accounted for by the social class variable. Several CVD risk factors were also adjusted for, however, these factors may not have been fully accounted for in the current analysis. We determined which factors were associated with both hearing loss and DP to ensure that true confounding factors were adjusted for, and we adjusted for similar potential confounding factors which have been previously used in the literature when examining diet and hearing loss ${ }^{(10,14,15,20,49)}$. Various models were investigated further since it is possible that BMI, SBP and total cholesterol could actually be intermediate markers rather than confounders and that we therefore overadjusted the models. A model of adjustment for age, occupation, smoking and PAL score was also investigated, excluding possible intermediate markers; however, effect sizes were very similar. Height was also explored in the models as a factor that cannot be affected by recent dietary intake, whereas BMI can; however, this did not greatly influence the models and therefore was not included in any further analyses.

DP analysis can also be relatively subjective and a number of arbitrary decisions were made, including how to best group food items into food groups, the number of patterns to be kept for the final analysis and the naming of the identified patterns $^{(42,48)}$. As an example, we decided to maintain several alcoholic beverage groups, instead of merging them, since health benefits of alcohol beverages have been suggested to differ depending on the type of beverage and the associated pattern of consumption; therefore, these groups were kept separate as we were interested in determining whether these might affect the produced DP.

An advantage of our analysis is the use of both FFQ and WI data, which produced similar DP. Spearman's correlation coefficients between the DP found using the FFQ and the WI ranged from 0.32 for the traditional patterns and healthy patterns, to 0.4 for the correlation between the high-sugar/lowalcohol patterns, which indicated a fairly weak to moderate but statistically significant correlation.

A recent study that carried out DP analysis in the same CaPS cohort as in this study found some similarities but also some differences ${ }^{(33)}$. They did not name their patterns. Indeed, it was difficult to name the DP in this study, which is one of the limitations of a posteriori DP analysis ${ }^{(48)}$. Mertens et al. ${ }^{(33)}$ found a mainly similar traditional pattern as in our study. Their second DP was different with a high intake of pulses as well as meat, fish, rice, pasta, fruit, vegetables and eggs. Our healthy pattern was similar in some ways with high factor loadings for cereals, vegetables and fruits. There was also a similar third pattern which was characterised by confectionery and sweet foods as 
Table 5. Ordinal logistic regression analysis of the association between categories of hearing loss (no hearing loss $\leq 25 \mathrm{~dB}$, mild $>25-40 \mathrm{~dB}$, moderate $>40-60 \mathrm{~dB}$, severe $>60 \mathrm{~dB}$ ) and quintiles $(\mathrm{Q})$ of dietary pattern factor score for weighed food intake data from the Caerphilly Prospective Study* (Odds ratios and $95 \%$ confidence intervals)

\begin{tabular}{|c|c|c|c|c|c|c|}
\hline & \multicolumn{6}{|c|}{ Dietary pattern } \\
\hline & \multicolumn{2}{|c|}{ Traditional } & \multicolumn{2}{|c|}{ Healthy } & \multicolumn{2}{|c|}{ High sugar/low alcoho } \\
\hline & OR & $95 \% \mathrm{Cl} \dagger$ & OR & $95 \% \mathrm{Cl} \dagger$ & OR & $95 \% \mathrm{Cl}+$ \\
\hline \multicolumn{7}{|l|}{ Model 1 - adjustment for age } \\
\hline Q1 (low pattern adherence; $n_{\max } 133$ ) & 1.00 & Ref. & 1.00 & Ref. & 1.00 & Ref. \\
\hline Q2 $\left(n_{\max } 133\right)$ & 2.09 & $1.21,3.62$ & 0.81 & $0.47,1.37$ & 0.77 & $0.45,1.32$ \\
\hline Q3 $\left(n_{\max } 133\right)$ & 2.03 & $1 \cdot 17,3.51$ & 0.82 & $0.49,1.39$ & 0.61 & $0.37,1.03$ \\
\hline Q4 $\left(n_{\max } 133\right)$ & 1.53 & $0.86,2 \cdot 70$ & 0.60 & $0.35,1.03$ & 0.82 & $0.48,1.37$ \\
\hline Q5 (high pattern adherence; $n_{\max } 133$ ) & 3.14 & $1.82,5.43$ & 0.45 & $0.26,0.77$ & 0.66 & $0.39,1.12$ \\
\hline Per fifth $\ddagger$ & 1.22 & $1.08,1.37$ & 0.83 & $0.73,0.94$ & 0.92 & $0.82,1.04$ \\
\hline$P_{\text {for trend }}$ & \multicolumn{2}{|c|}{0.001} & \multicolumn{2}{|c|}{0.002} & \multirow{2}{*}{\multicolumn{2}{|c|}{0.19}} \\
\hline Model 2 - adjustment for age and occupa & & & & & & \\
\hline Q1 $\left(n_{\max } 133\right)$ & 1.00 & Ref. & 1.00 & Ref. & 1.00 & Ref. \\
\hline Q2 $\left(n_{\max } 133\right)$ & 2.09 & $1.20,3.66$ & 0.87 & $0.51,1.49$ & 0.81 & $0.47,1.40$ \\
\hline Q3 $\left(n_{\max } 133\right)$ & 1.93 & $1 \cdot 10,3 \cdot 39$ & 0.98 & $0.57,1.67$ & 0.67 & $0.39,1.13$ \\
\hline Q4 $\left(n_{\max } 133\right)$ & $1 \cdot 30$ & $0 \cdot 72,2 \cdot 34$ & 0.72 & $0.42,1.25$ & 0.91 & $0.53,1.54$ \\
\hline Q5 $\left(n_{\max } 133\right)$ & $2 \cdot 68$ & $1.53,4.68$ & 0.57 & $0.32,1.02$ & 0.73 & $0.43,1.25$ \\
\hline Per fifth $\ddagger$ & 1.17 & $1.03,1.32$ & 0.88 & $0.78,1.00$ & 0.95 & $0.84,1.07$ \\
\hline$P_{\text {for trend }}$ & \multicolumn{2}{|c|}{0.02} & \multicolumn{2}{|r|}{0.06} & \multicolumn{2}{|r|}{0.40} \\
\hline \multicolumn{7}{|c|}{$\begin{array}{l}\text { Model } 3 \text { - adjustment for age, occupation, BMI, systolic } \\
\text { blood pressure, smoking, physical activity level and total cholesterol }\end{array}$} \\
\hline Q1 $\left(n_{\max } 133\right)$ & 1.00 & Ref. & 1.00 & Ref. & 1.00 & Ref. \\
\hline Q2 $\left(n_{\max } 133\right)$ & 2.04 & $1 \cdot 15,3 \cdot 62$ & 0.81 & $0.47,1.42$ & 0.82 & $0.47,1.44$ \\
\hline Q3 $\left(n_{\max } 133\right)$ & 1.98 & $1.11,3.53$ & 0.99 & $0.56,1.74$ & 0.69 & $0.40,1.20$ \\
\hline Q4 $\left(n_{\max } 133\right)$ & 1.36 & $0.74,2.50$ & 0.68 & $0.38,1.22$ & 0.77 & $0.44,1.35$ \\
\hline Q5 $\left(n_{\max } 133\right)$ & 2.68 & $1.50,4.79$ & 0.55 & $0.30,1.02$ & 0.78 & $0.44,1.37$ \\
\hline Per fifth $\ddagger$ & $1 \cdot 17$ & $1.03,1.33$ & 0.87 & $0.76,1.00$ & 0.94 & $0.83,1.07$ \\
\hline$P_{\text {for trend }}$ & \multicolumn{2}{|r|}{0.02} & \multicolumn{2}{|r|}{0.06} & \multicolumn{2}{|r|}{0.37} \\
\hline
\end{tabular}

DP, dietary pattern; Ref., reference.

* Categories of hearing loss; no hearing loss $\leq 25 \mathrm{~dB}$, mild $>25-40 \mathrm{~dB}$, moderate $>40-60 \mathrm{~dB}$, severe $>60 \mathrm{~dB}$.

† OR of having greater hearing loss (reference; severe hearing loss) for those in each quintile of DP (reference; Q1).

$\ddagger$ OR for a one-unit increase in hearing loss category for each higher quintile of DP.

Table 6. Summary table of logistic and ordinal logistic regression analyses of the association between hearing loss $(\mathrm{HL})(\mathrm{pure}-\mathrm{tone}$ average $(\mathrm{PTA})>25 \mathrm{~dB}$ for logistic regression and categories of hearing loss; no hearing loss $\leq 25 \mathrm{~dB}$, mild $>25-40 \mathrm{~dB}$, moderate $>40-60 \mathrm{~dB}$ and severe $>60 \mathrm{~dB}$ for ordinal logistic regression) and quintiles $(Q)$ of dietary pattern factor score (Q1-Q5) after full adjustment for potential confounding factors* for $F F Q$ and weighed food intake (WI) data from the Caerphilly Prospective Study

(Odds ratios and $95 \%$ confidence intervals)

\begin{tabular}{|c|c|c|c|c|c|c|c|c|c|c|c|c|}
\hline & \multicolumn{12}{|c|}{ Dietary pattern } \\
\hline & \multicolumn{2}{|c|}{ Traditional FFQ } & \multicolumn{2}{|c|}{ Traditional WI } & \multicolumn{2}{|c|}{ Healthy FFQ } & \multicolumn{2}{|c|}{ Healthy WI } & \multicolumn{2}{|c|}{$\begin{array}{l}\text { High sugar/low } \\
\text { alcohol FFQ }\end{array}$} & \multicolumn{2}{|c|}{$\begin{array}{l}\text { High sugar/low } \\
\text { alcohol WI }\end{array}$} \\
\hline & OR & $95 \% \mathrm{Cl}$ & OR & $95 \% \mathrm{Cl}$ & OR & $95 \% \mathrm{Cl}$ & OR & $95 \% \mathrm{Cl}$ & OR & $95 \% \mathrm{Cl}$ & OR & $95 \% \mathrm{Cl}$ \\
\hline \multicolumn{13}{|l|}{ Logistic regression (HL-PTA > $25 \mathrm{~dB}) \dagger$} \\
\hline $\begin{array}{l}\text { OR per fifth } \ddagger \\
P\end{array}$ & 1.03 & $\begin{array}{l}0.96,1.11 \\
0.44\end{array}$ & $1 \cdot 18$ & $\begin{array}{l}1.02,1.35 \\
0.02\end{array}$ & 0.83 & $\begin{array}{l}0.77,0.90 \\
<0.001\end{array}$ & 0.85 & $\begin{array}{l}0.73,0.99 \\
0.03\end{array}$ & 1.06 & $\begin{array}{l}0.98,1.14 \\
0.16\end{array}$ & 0.97 & $\begin{array}{l}0.85,1.12 \\
0.69\end{array}$ \\
\hline \multicolumn{13}{|l|}{ Ordinal logistic regression (HL-PTA $>25 \mathrm{~dB}) \S$} \\
\hline $\begin{array}{l}\text { OR per fifth } \ddagger \\
P_{\text {for trend }}\end{array}$ & 1.04 & $\begin{array}{l}0.98,1.12 \\
0.20\end{array}$ & $1 \cdot 17$ & $\begin{array}{l}1.03,1.33 \\
0.02\end{array}$ & 0.87 & $\begin{array}{l}0.81,0.94 \\
<0.001\end{array}$ & 0.87 & $\begin{array}{l}0.76,1.00 \\
0.06\end{array}$ & 1.05 & $\begin{array}{l}0.98,1.13 \\
0.14\end{array}$ & 0.94 & $\begin{array}{l}0.83,1.07 \\
0.37\end{array}$ \\
\hline
\end{tabular}

* Adjustment for age, occupation, BMI, systolic blood pressure, smoking, physical activity level and total cholesterol.

$\dagger$ Hearing loss defined as PTA $>25 \mathrm{~dB}$ for logistic regression.

$\ddagger$ OR for hearing loss per fifth of dietary pattern factor score.

$\S$ Categories of hearing loss; no hearing loss $\leq 25 \mathrm{~dB}$, mild $>25-40 \mathrm{~dB}$, moderate $>40-60 \mathrm{~dB}$, severe $>60 \mathrm{~dB}$.

well as avoidance of alcohol ${ }^{(33)}$. This analysis, however, differed from our analysis as they used dietary questionnaires from phases 2 and 3 of the CAPS, which took place over a period of 5 years, to generate their DP, hence similar DP would not necessarily be expected ${ }^{(33)}$. A limitation of our study is the derivation of DP from data that are over 40 years old; therefore, as found in the study by Mertens et al., DP would have changed since then ${ }^{(33)}$.

The issue of whether to adjust for energy intake in DP analysis is debatable ${ }^{(50,51)}$. Energy requirements vary according to 
age, sex, BMI and PAL; therefore, as the overall food intake will differ by these factors, it is generally considered more appropriate to adjust for energy intake in analyses of dietary intake. Energy adjustment is required for a number of reasons; to control for confounding, to give a measure of dietary composition, not just dietary intake, and to mitigate the effects of measurement error ${ }^{(49,51)}$. In this current analysis, adjustment for energy intake of the WI data did not appreciably alter effect sizes. In previous studies, adjustment for energy intake did slightly alter factor loadings and derived DP but did not greatly alter the associations with variables such as birthweight ${ }^{(52,53)}$.

Furthermore, there is a relatively small amount of variance in dietary data explained by the three DP. This could be perhaps due to other DP also being present in this cohort. It was also not possible to measure change in diet or hearing loss as these both were assessed only once. This is a limitation particularly because auditory assessment was assessed only once, that is, 5 years after dietary assessment.

\section{Conclusion}

Hearing loss can have a significant detrimental impact on a person's emotional health and can be very isolating and debilitating. We found that a healthy DP was significantly and inversely associated with the prevalence of hearing loss in older men aged 45-59 years in the CaPS. This demonstrates that a healthy diet may contribute to a reduced risk of hearing loss. However, the role of dietary factors in hearing loss remains to be fully established and warrants further investigation using robust exposure and end point assessment.

\section{Acknowledgements}

The present analysis was completed by N. E. G while at Queen's University, funded by a $\mathrm{PhD}$ studentship from the Department for Employment and Learning Funding, Northern Ireland, UK.

J. Y., J. E. G., Y. B.-S. and A. F. designed research; J. Y., J. E. G., A. F. acquisition of data; N. E. G., C. C. P., C. E. N. and N. L. analysed data; N. E. G. wrote paper; C. E. N., C. C. P., J. Y., N. E. G., Y. B.-S. and J. V. W. critical revision of manuscript; and N. E. G. and J. V. W. had primary responsibility for final content.

All authors read and approved the final manuscript. Authors have no potential conflicts of interest.

\section{Supplementary material}

For supplementary material/s referred to in this article, please visit https://doi.org/10.1017/S0007114519000175

\section{References}

1. Dalton DS, Cruickshanks KJ, Klein BE, et al. (2003) The impact of hearing loss on quality of life in older adults. Gerontologist 43, 661-668.

2. Lotfi Y, Mehrkian S, Moossavi A, et al. (2009) Quality of life improvement in hearing-impaired elderly people after wearing a hearing aid. Arch Iran Med 12, 365-370.
3. Li CM, Zhang X, Hoffman HJ, et al. (2014) Hearing impairment associated with depression in US adults, National Health and Nutrition Examination Survey 2005-2010. JAMA Otolaryngol Head Neck Surg 140, 293-302.

4. Gopinath B, Wang JJ, Schneider J, et al. (2009) Depressive symptoms in older adults with hearing impairment: the Blue Mountains Hearing Study. J Am Geriatr Soc 57, 1306-1308.

5. Boi R, Racca L, Cavallero A, et al. (2012) Hearing loss and depressive symptoms in elderly patients. Geriatr Gerontol Int 12, $440-445$.

6. Lin FR, Yaffe K, Xia J, et al. (2013) Hearing loss and cognitive decline in older adults. JAMA Intern Med 173, 293-299.

7. Moore DR, Edmondson-Jones M, Dawes P, et al. (2014) Relation between speech-in-noise threshold, hearing loss and cognition from 40-69 years of age. PLOS ONE 9, e107720.

8. Lin FR, Thorpe R, Gordon-Salant S, et al. (2011) Hearing loss prevalence and risk factors among older adults in the United States. J Gerontol A Biol Sci Med Sci 66, 582-590.

9. Williamson JD \& Fried LP (2015) Characterization of older adults who attribute functional decrements to "old age". J Am Geriatr Soc 44, 1429-1434.

10. Gopinath B, Flood VM, Rochtchina E, et al. (2010) Consumption of omega-3 fatty acids and fish and risk of agerelated. Am J Clin Nutr 92, 416-421.

11. Torre P, Cruickshanks KJ, Klein BE, et al. (2005) The association between cardiovascular disease and cochlear function in older adults. J Speech Lang Hear Res 48, 473-481.

12. Curhan SG, Eavey RD, Wang M, et al. (2014) Fish and fatty acid consumption and the risk of hearing loss in women. $A m J$ Clin Nutr 100, 1371-1377.

13. Rosenhall U, Idrizbegovic E, Hederstierna C, et al. (2015) Dietary habits and hearing. Int $J$ Audiol 54, Suppl. 1, S53-S56.

14. Choi YH, Miller JF, Tucker KL, et al. (2014) Antioxidant vitamins and magnesium and the risk of hearing loss in the US general population. Am J Clin Nutr 99, 148-155.

15. Gopinath B, Flood VM, McMahon CM, et al. (2011) Dietary antioxidant intake is associated with the prevalence but not incidence of age-related hearing loss. J Nutr Health Aging $\mathbf{1 5}$, 896-900.

16. Houston DK, Johnson MA, Nozza RJ, et al. (1999) Age-related hearing loss, vitamin B-12, and folate in elderly women. $\mathrm{AmJ}$ Clin Nutr 69, 564-571.

17. Lasisi AO, Fehintola FA \& Yusuf OB (2010) Age-related hearing loss, vitamin $\mathrm{B}_{12}$, and folate in the elderly. Otolaryngol Head Neck Surg 143, 826-830.

18. Péneau S, Jeandel C, Déjardin P, et al. (2013) Intake of specific nutrients and foods and hearing level measured 13 years later. Br J Nutr 109, 2079-2088.

19. Popelka MM, Cruickshanks KJ, Wiley TL, et al. (2000) Moderate alcohol consumption and hearing loss: a protective effect. J Am Geriatr Soc 48, 1273-1278.

20. Shargorodsky J, Curhan SG, Eavey R, et al. (2010) A prospective study of vitamin intake and the risk of hearing loss in men. Otolaryngol Head Neck Surg 142, 231-236.

21. Gopinath B, Flood VM, Teber E, et al. (2011) Dietary intake of cholesterol is positively associated and use of cholesterollowering medication is negatively associated with prevalent age-related hearing loss. J Nutr 141, 1355-1361.

22. Gopinath B, Flood VM, McMahon CM, et al. (2010) Dietary glycemic load is a predictor of age-related hearing loss in older adults. J Nutr 140, 2207-2212.

23. Rosenhall U, Sixt E, Sundh V, et al. (1993) Correlations between presbyacusis and extrinsic noxious factors. Audio$\log y$ 32, 234-243. 
24. Curhan SG, Stankovic KM, Eavey RD, et al. (2015) Carotenoids, vitamin $\mathrm{A}$, vitamin $\mathrm{C}$, vitamin $\mathrm{E}$, and folate and risk of self-reported hearing loss in women. Am J Clin Nutr 102, $1167-1175$.

25. Curhan SG, Eavey R, Wang M, et al. (2015) Prospective study of alcohol consumption and self-reported hearing loss in women. Alcohol 49, 71-77.

26. Hu FB (2002) Dietary pattern analysis: a new direction in nutritional epidemiology. Curr Opin Lipidol 13, 3-9.

27. Ambrosini GL, O'Sullivan TA, de Klerk NH, et al. (2011) Relative validity of adolescent dietary patterns: a comparison of a food frequency questionnaire and 3-day food record. Br J Nutr 105, 625-633.

28. Bountziouka V, Tzavelas G, Polychronopoulos E, et al. (2011) Validity of dietary patterns derived in nutrition surveys using a priori and a posteriori multivariate statistical methods. Int J Food Sci Nutr 62, 617-627.

29. Spankovich C \& Le Prell CG (2013) Healthy diets, healthy hearing: National Health and Nutrition Examination Survey, 1999-2002. Int J Audiol 52, 369-376.

30. Kastorini CM, Papadakis G, Milionis HJ, et al. (2013) Comparative analysis of a-priori and a-posteriori dietary patterns using state-of-the-art classification algorithms: a case/casecontrol study. Artif Intell Med 59, 175-183.

31. University of Bristol (2014) Caerphilly Prospective Study. http://www.bris.ac.uk/social-community-medicine/projects/ caerphilly/about/ (accessed May 2016).

32. Bainton D, Miller NE, Bolton CH, et al. (1992) Plasma triglyceride and high density lipoprotein cholesterol as predictors of ischaemic heart disease in British men. The Caerphilly and Speedwell Collaborative Heart Disease Studies. Br Heart $J$ 68, 60-66.

33. Mertens E, Markey O, Geleijnse JM, et al. (2017) Dietary patterns in relation to cardiovascular disease incidence and risk markers in a middle-aged British male population: data from the Caerphilly Prospective Study. Nutrients 9, E75.

34. MRC Epidemiology Unit Cardiff (1985) The Caerphilly Collaborative Heart Disease Studies: Project Description and Manual of Operations. Cardiff: MRC Epidemiology Unit.

35. Yarnell JW, Fehily AM, Milbank JE, et al. (1983) A short dietary questionnaire for use in an epidemiological survey: comparison with weighed dietary records. Hum Nutr Appl Nutr 37, 103-112.

36. Elwood PC, Strain JJ, Robson PJ, et al. (2005) Milk consumption, stroke, and heart attack risk: evidence from the Caerphilly cohort of older men. $J$ Epidemiol Community Health 59, 502-505.

37. Gallacher J, Ilubaera V, Ben-Shlomo Y, et al. (2012) Auditory threshold, phonologic demand, and incident dementia. Neurology 79, 1583-1590.
38. Yarnell JW, Patterson CC, Thomas HF, et al. (2001) Central obesity: predictive value of skinfold measurements for subsequent ischaemic heart disease at 14 years follow-up in the Caerphilly Study. Int J Obes Relat Metab Disord 25, 1546-1549.

39. Yu S, Patterson CC \& Yarnell JW (2008) Is vigorous physical activity contraindicated in subjects with coronary heart disease? Evidence from the Caerphilly study. Eur Heart $J$ 29, 602-608.

40. Fehily AM, Phillips KM \& Yarnell JW (1984) Diet, smoking, social class, and body mass index in the Caerphilly Heart Disease Study. Am J Clin Nutr 40, 827-833.

41. Office of Population Censuses and Surveys (1980) Classification of occupations and coding index. London: Her Majesty's Stationery Office.

42. Michels KB \& Schulze MB (2005) Can dietary patterns help us detect diet-disease associations? Nutr Res Rev 18, 241-248.

43. Gopinath B, Schneider J, Flood VM, et al. (2014) Association between diet quality with concurrent vision and hearing impairment in older adults. J Nutr Health Aging 18, 251-256.

44. Helzner EP, Patel AS, Pratt S, et al. (2011) Hearing sensitivity in older adults: associations with cardiovascular risk factors in Health, Aging and Body Composition Study. J Am Geriatr Soc 59, 972-979.

45. Park S, Johnson MA, Shea Miller K, et al. (2007) Hearing loss and cardiovascular disease risk factors in older adults. J Nutr Health Aging 11, 515-518.

46. Rosenhall U \& Sundh V (2006) Age-related hearing loss and blood pressure. Noise Heal 8, 88-94.

47. Park S (2006) Hearing impairment, cardiovascular disease risk factors, methylmalonic acid and vitamin $\mathrm{B}_{12}$ status in older adults. $\mathrm{PhD}$ thesis, University of Georgia, Georgia.

48. Reedy J, Wirfält E, Flood A, et al. (2010) Comparing 3 dietary pattern methods-cluster analysis, factor analysis, and index analysis-with colorectal cancer risk. Am J Epidemiol 171, 479-487.

49. Gopinath B, Flood VM, McMahon CM, et al. (2010) The effects of smoking and alcohol consumption on age-related hearing loss: the Blue Mountains Hearing Study. Ear Hear 31, 277-282.

50. Newby PK \& Tucker KL (2004) Empirically derived eating patterns using factor or cluster analysis: a review. Nutr Rev $\mathbf{6 2}$, $177-203$.

51. Willett WC, Howe GR \& Kushi LH (1997) Adjustment for total energy intake in epidemiologic studies. Am J Clin Nutr $\mathbf{6 5}$, Suppl, 1220S-1228S.

52. Balder HF, Virtanen M, Brants HA, et al. (2003) Common and country-specific dietary patterns in four European cohort studies. J Nutr 133, 4246-4251.

53. Northstone K, Ness AR, Emmett PM, et al. (2008) Adjusting for energy intake in dietary pattern investigations using principal components analysis. Eur J Clin Nutr 62, 931-938. 